\title{
sciendo
}

10.2478/AMB-2019-0025

\section{THE ROLE OF CONTROL IN THE EFFECTIVE HOSPITAL MANAGEMENT}

\author{
M. Lazarova, T. Zlatanova \\ Department of Healthcare Economics, Faculty of Public Health, Medical University - Sofia, Bulgaria
}

\begin{abstract}
The objective of the present study was to investigate the opinion of the managers working in the health system concerning their attitude towards the operations of control within the system and the impact of these operations on the activity of the healthcare institutions. Materials and Methods: From October 2016 till January 2017 using an anonymous questionnaire we studied the opinion of 407 medical doctors, medical and healthcare specialists working in various types of healthcare institutions for hospital care in Sofia and the countryside. Results: Only 1/5 of the respondents shared the opinion that the adequate control resulted in quality improvement of the provided medical caregiving, one in four $(25,8 \%)$ believed that the control could raise the responsibilities of the officials with managerial titles; one in three $(34,2 \%)$ shared the opinion it improved the responsibilities of the executives. Conclusion: The new operational terms and conditions implemented in the health insurance system do not result in improving the work quality in the hospital, which allows the conclusion that by changing only the healthcare funding the desired positive changes could not be attained. The organization, management and provision of medical care should be generally revised.
\end{abstract}

Key words: control, effectiveness, resources, management

Corresponding author: M. Lazarova, Department of Healthcare Economics, Faculty of Public Health, Medical University, 8, Byalo More str., 1527 Sofia, Bulgaria, e-mail: maria.benkovska77@gmail.com

\section{INTRODUCTION}

E ach healthcare system requires unity and interaction of health resources, management, quality of the offered healthcare and population's health results. The amount of resources quantity/quality, always depends on a country's economic development and on the society's capacity to save "money for health". Hence, the management effectiveness is an essential point - i.e. the relation of the received result with the resources of a particular healthcare organization $[7,8]$.

From an administrative point of view, the control activities could be presented as an activity for clarifying the actual position in terms of statute and operations of the controlled organs, their assessment in conformity with the defined objectives of the management system and as undertaking particular resolving impacts. Its essence is inevitably present in the management system, so the prerequisites for eliminating the unfavourable deviations are created, aimed at unveiling and preventing the prerequisites for error occurrence [1, 2, 9].

The various health systems are effective to different degrees and this depends not only on the resources' amount, set aside by a particular country for the health of its population, but also on the purposeful and socially acceptable healthcare policy being im- 
plemented with the necessary continuity and consistency, as well as the effective management of health system that ensures patients safety, security and satisfaction $[3,4,5,6]$.

The objective of the present study was to investigate the opinion shared by the managers in the health system regarding their attitude towards the control operations within the system and the impact of these operations on the activity of the healthcare institutions.

\section{METHODS}

To achieve the objectives, we set the following tasks:

- Analysis of the necessary control depending on the healthcare institution type, according to the opinion of the questionnaire respondents;

- The impact of control being exercised by the $\mathrm{Na}$ tional Health Insurance Fund onto the activity being performed depending on the settlement according to the opinion of the questionnaire respondents;

- Definition of recommendations in order to optimize the control at the hospital medical care level.

The opinion of 407 doctors, medical specialists and healthcare specialists working in various types of healthcare institutions for hospital care was studied by an anonymous questionnaire. The questionnaire research was conducted in the period from October 2016 to January 2017 in Sofia and the countryside. All the participants were asked 30 questions concerning their contractual relations with the National Health Insurance Fund, the controlling operations on behalf of the institution and their relation to the healthcare reform being performed.

\section{RESULTS}

Within the questioned 407 people, the women prevailed $(315-77,4 \%)$ (Figure 1).

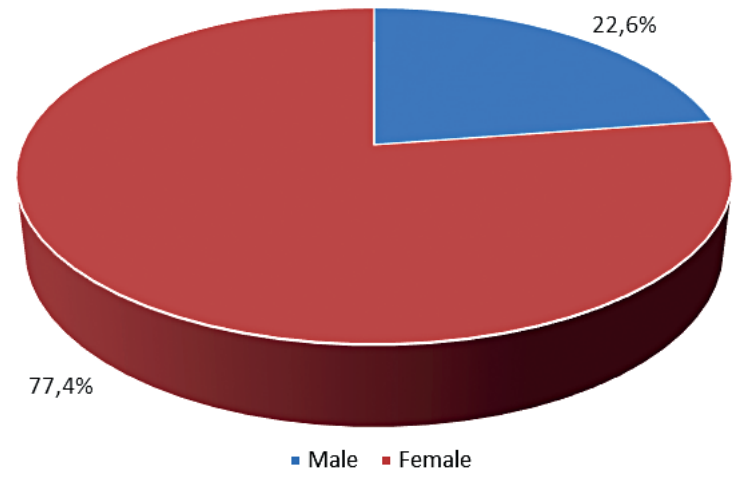

Fig. 1. The participants' sexes shown
The average age of the participants in the questionnaire-based study was 55 (ranging from 23 to 75 years).

A little more than half of the questioned participants were in the capital $(54,1 \%)$, whereas one in four $(28,5 \%)$ worked in a district centre, and the remaining $17,4 \%$ - in a municipal centre. It is worth mentioning that this distribution varies significantly in view of sex $(p<0,05)$, whereas the highest share was the one of women in the capital and of men - in the district centres (figure 2).

Among the participants in the questionnaire the hospital directors were only $2 \%$, the chiefs of clinics $-3,5 \%$, and the heads of wards $-14,8 \%$, while the remaining $79,8 \%$ chose other answers. Among them the most numerous were the healthcare professionals $(27,3 \%)$, followed by the doctors $(25,3 \%)$ and senior or head nurse $(17,7 \%)$. We questioned administration representatives $(3,4 \%)$, heads of departments/sectors $(2,2 \%)$ and managers or Executive Officers (1\%) (figure 3 ). Both sexes were differently represented among these positions: $34,8 \%$ of males are heads of wards, while this is true in just $8,9 \%$ of females; half the males have checked "other occupation", while $87,2 \%$ of the females have checked this category. The high ranking positions - director of hospital and chief of clinic, are represented by very few people and no firm conclusions could be drawn from their distribution. The distribution of the job positions in view of their settlement is an indirect mark of the difficult access to managerial personnel: among the included ones in the capital most often we could see representatives checking "other", while the heads of wards were available more often in the district and especially in the municipal centres. Among the hospital directors there is not a single person questioned in the capital and because of the low number of such persons it is not possible to draw valid conclusions.

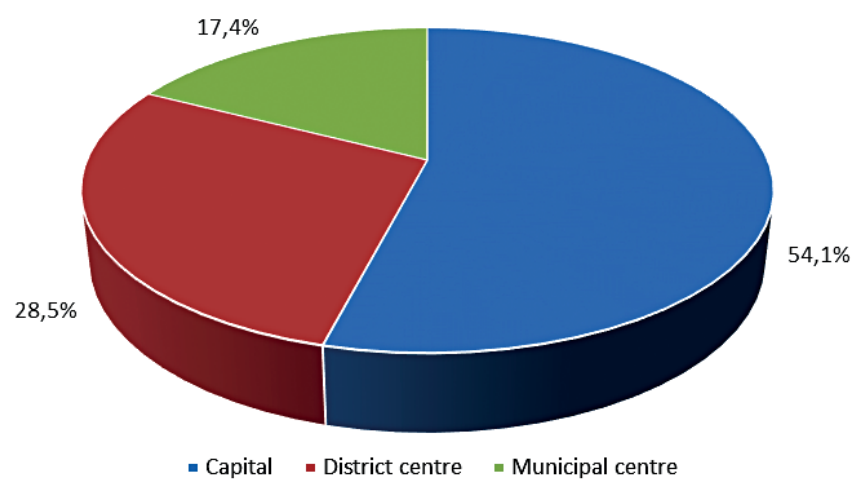

Fig. 2. The participants' distribution in view of their settlement 


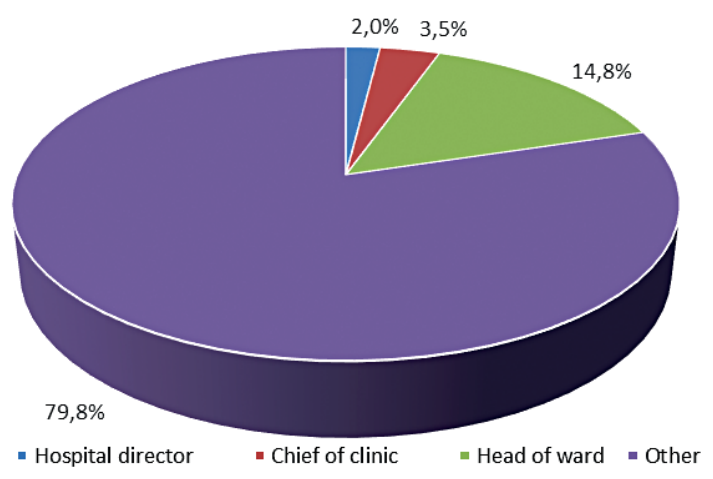

Fig. 3. Distribution of the participating respondents based on their job title

Analysis of the necessary control depending on the type of the healthcare institution, and according to the respondents' opinion

The highest percentage is the one of participating employees in the state healthcare institutions $(50,4 \%)$. The second ranking are the municipal healthcare institutions $(36,4 \%)$, and the third ranking are the private healthcare institutions $(12,8 \%)$. Only $0,5 \%$ of the participants are from other healthcare institutions (figure 4). It is worth mentioning that the higher proportion of men was found in state healthcare institutions, while the proportion of women was higher in the municipal ones. The distribution of the healthcare institution's type in terms of settlement depends on their actual distribution throughout the country. Thus, for example, the municipal healthcare institutions prevail in the municipal centres, where we could almost not see stateowned and private healthcare institutions. The number of the participating directors of hospitals of municipal and private healthcare institutions is one and the same, followed by nearly $90 \%$ of the chiefs of clinics in the state healthcare institutions and somewhat above half of the heads of wards in the state-owned healthcare institutions. 49\% checked "something else" as a job title. The ones questioned in the municipal and the private healthcare institutions are very few.

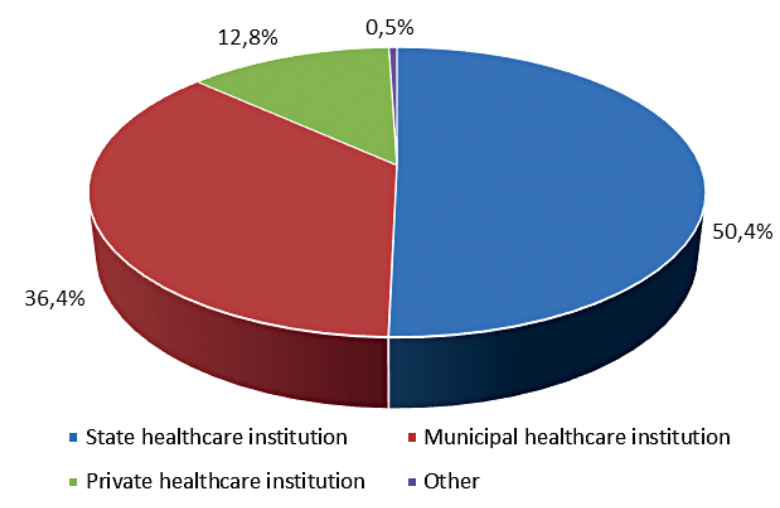

Fig. 4. Distribution of the questioned persons in terms of healthcare institution type
Impact of the control exercised by the National Health Insurance Fund on the daily activity depending on the settlement (according to the opinion of the respondents)

It is encouraging that $71 \%$ of the respondents found the control exercised on the performance of the contracts for providing medical cares on behalf of the $\mathrm{Na}$ tional Health Insurance Fund as necessary, 14,7\% provided a negative answer, $12,8 \%$ had no opinion, and 1,5\% provided another answer (figure 5). Most of them replied positively, whereas the control was necessary and these were located in the municipal centres, showing a minimum difference with the ones who answered positively in the capital. Only half of the participants in the district centres agreed with this. Around $15 \%$ of the respondents from all the settlements answered negatively, yet it is troublesome that around $24 \%$ of the questioned persons in the district centres had no opinion concerning the issue (table 1). Based on the analysis of the answers to the question concerning the need of control on the performance of the contracts for providing medical cares on behalf of the National Health Insurance Fund in the hospitals we could draw the conclusion that changes should be implemented for improving the control and its effectiveness.

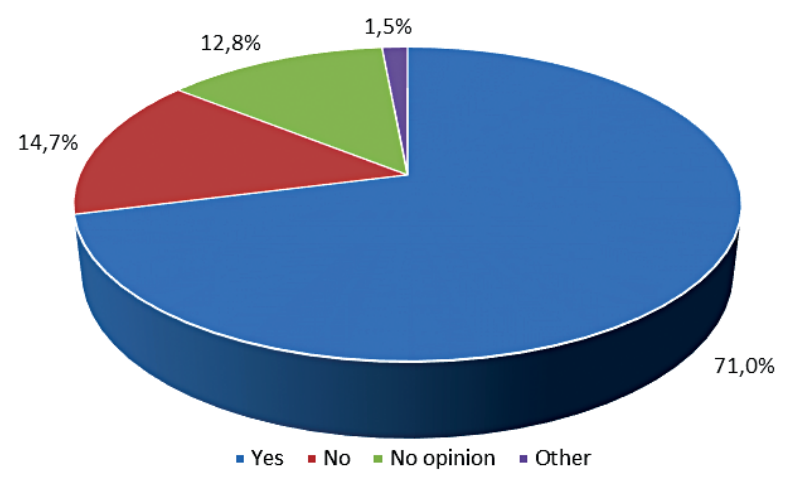

Fig. 5. Distribution of the answers to the question "Do we need control on the performance of the contracts for providing medical care by the hospitals on behalf of the National Health Insurance Fund?"

According to the respondents, the proper control could fully impact the personnel's work being done in $37,1 \%$ of the cases, partly in $32,4 \%$ of the cases, and it has no impact in $25,6 \%$ of the cases (figure 6 ). One in twenty $(4,4 \%)$ has no opinion concerning this question, and $0,5 \%$ have chosen the answer "something else" (with an additional choice "In some cases "yes"). Men more often answered positively, while women - chose the answer "partly". More positive answers and answers "partly" gave the respondents in the municipal centres, while fewer in the capital with the lowest numbers in the district centres. Corre- 
spondingly, the highest per cent of negative answers was the one in the district centres, followed by the capital and the municipal centres (table 2). The high- est number of positive answers (over 3/4) was provided by the directors of hospitals and nearly $2 / 3$ of the chiefs of clinics.

Table 1. Necessity for control on the performance of the contracts for providing medical cares on behalf of the National Health Insurance Fund according to the respondents

\begin{tabular}{|c|c|c|c|c|c|c|c|c|}
\hline \multirow{3}{*}{\multicolumn{2}{|c|}{ Question/ answer }} & \multicolumn{6}{|c|}{ Settlement } & \multirow{3}{*}{$p$} \\
\hline & & \multicolumn{2}{|c|}{ Capital } & \multicolumn{2}{|c|}{ District centre } & \multicolumn{2}{|c|}{ Municipal centre } & \\
\hline & & $\mathrm{n}$ & $\%$ & $\mathrm{n}$ & $\%$ & $\mathrm{n}$ & $\%$ & \\
\hline \multirow{4}{*}{$\begin{array}{l}\text { Do we need control on the perfor- } \\
\text { mance of the contracts for provid- } \\
\text { ing medical care by the hospitals } \\
\text { on behalf of the National Health } \\
\text { Insurance Fund }\end{array}$} & Yes & 166 & $75,5 \%$ & 67 & $57,8 \%$ & 56 & $78,9 \%$ & \multirow{4}{*}{0,003} \\
\hline & No & 30 & $13,6 \%$ & 20 & $17,2 \%$ & 10 & $14,1 \%$ & \\
\hline & No opinion & 20 & $9,1 \%$ & 27 & $23,3 \%$ & 5 & $7,0 \%$ & \\
\hline & Other & 4 & $1,8 \%$ & 2 & $1,7 \%$ & 0 & $0,0 \%$ & \\
\hline
\end{tabular}

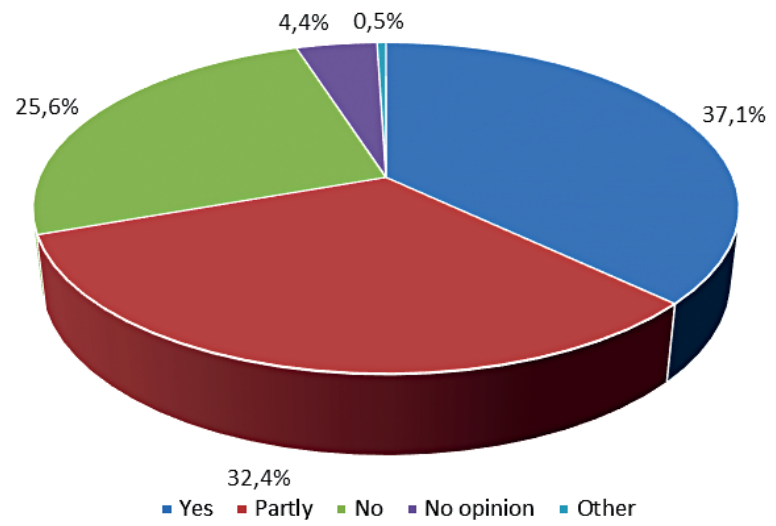

Table 2. Opinion of the respondents concerning the impact of the control exercised by the National Health Insurance Fund on the activity being performed
Fig. 6. Distribution of the answers to the question "Does the control being exercised by the National Health Insurance Fund impact the activity performed by you?"

\begin{tabular}{|c|c|c|c|c|c|c|c|c|}
\hline \multirow{3}{*}{\multicolumn{2}{|c|}{ Question/answer }} & \multicolumn{6}{|c|}{ Settlement } & \multirow{3}{*}{$p$} \\
\hline & & \multicolumn{2}{|c|}{ Capital } & \multicolumn{2}{|c|}{ District centre } & \multicolumn{2}{|c|}{ Municipal centre } & \\
\hline & & $\mathrm{n}$ & $\%$ & $\mathrm{n}$ & $\%$ & $n$ & $\%$ & \\
\hline \multirow{5}{*}{$\begin{array}{l}\text { Does the control being exer- } \\
\text { cised by the National Health } \\
\text { Insurance Fund impact the } \\
\text { activity performed by you }\end{array}$} & Yes & 82 & $37,3 \%$ & 36 & $31,0 \%$ & 33 & $46,5 \%$ & \multirow{5}{*}{0,002} \\
\hline & Partly & 74 & $33,6 \%$ & 34 & $29,3 \%$ & 24 & $33,8 \%$ & \\
\hline & No & 56 & $25,5 \%$ & 36 & $31,0 \%$ & 12 & $16,9 \%$ & \\
\hline & No opinion & 8 & $3,6 \%$ & 10 & $8,6 \%$ & 0 & $0,0 \%$ & \\
\hline & Other & 0 & $0,0 \%$ & 0 & $0,0 \%$ & 2 & $2,8 \%$ & \\
\hline
\end{tabular}

According to $20,9 \%$ of the respondents the control results in improving the quality of the provided medical care; to $16,5 \%$ it does not seem to impact the quality of the medical care; $6,4 \%$ are of the opinion that it lowers the quality of the provided medical care; one in four $(25,8 \%)$ shares the opinion that control results in raising the responsibilities of the officials holding managerial positions; one in three $(34,2 \%)$ shares the opinion that it raises the responsibility of the executives and $13,5 \%$ - that it hinders the activi- ties being performed in the hospital. The aggregate of the relative percentages exceeds 100 , since the participants have chosen more than one answer (figure 7 ). Over $3 / 4$ of the directors of hospitals, chiefs of clinics, heads of wards and the others holding "other" title have answered that the control does not result in lowering the quality of the provided medical care. At the same time nearly $100 \%$ of all the officials holding managerial titles have chosen the answer "something else" about the control results. According to many of 
the respondents (nearly $80 \%$ ) with various professional experiences the control impacts the quality of the provided medical care being, whereas once again unanimously they believe this does not result in lowering the quality of these medical cares. Additionally, more than half have answered that exercising the control does not result in improving the responsibility of the officials and does not hinder the activities being performed in the hospital. Almost unanimously, $3 / 4$ of the employees in all healthcare institutions have answered that the controlling functions do not result in improving the quality of the provided medical care being and has no impact on its quality.

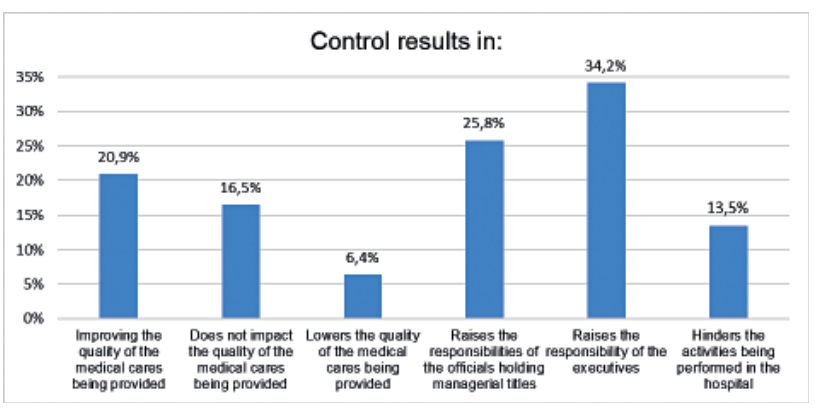

Fig. 7. Distribution of the answers to the question "According to you, the control results in:"

Very few respondents share the opinion that the quality of the work in their healthcare institution has improved related to the conditions of the healthcare insurance (only $7,4 \%)$. One in three $(31,7 \%)$ admit- ted partial changes in positive direction, and half of the respondents $(51,1 \%)$ showed the opinion that the work quality has not improved since the year 2000 . One in ten $(9,3 \%)$ do not have an opinion and $0,5 \%$ have answered something else (figure 8).

The highest proportion of those providing negative answers was in the municipal centres (around 61\%), followed by the respondents in the district centres (around $51 \%$ ) with $48 \%$ answering negatively in the capital city. A bit more than half the respondents from the capital have answered positively and "partially positively" whereas it is interesting to mention that nobody answered positively in the municipal centres (table 3 ). The officials in managerial positions provided versatile answers to this question whereas the directors of hospitals are divided in two parts: half of them have answered positively and the other half negatively. A bit more than half of the heads of wards have chosen the answer "partially", and over half of the chiefs of clinics have answered negatively. Once again, $100 \%$ of the employees in other healthcare institutions have answered negatively followed by those in municipal and private healthcare institutions.

The prevailing opinion is that the new operational conditions within the health insurance system do not result in improving the quality of work in the hospital, therefore we can draw the conclusion that only by changing the healthcare funding the desired positive changes could be brought. We should change the organization, management and provision of medical care.

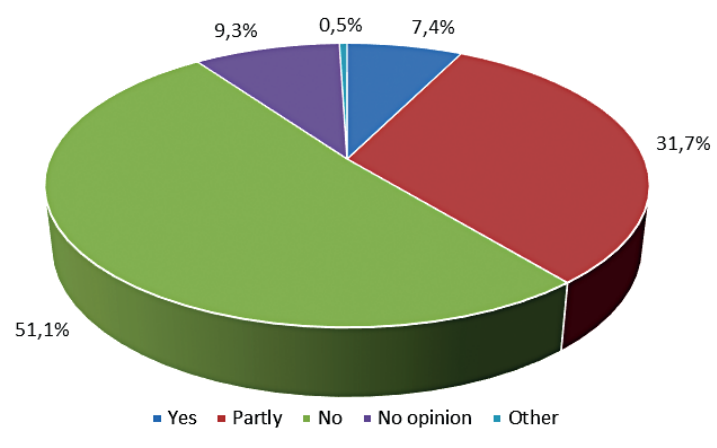

Fig. 8. Distribution of the opinion shared by the respondents concerning the improvement of the work quality in the hospital in relation to the healthcare insurance (after 2000)

Table 3. Opinion shared by the respondents on the change of work quality in the hospital since the year 2000 depending on the hospital location

\begin{tabular}{|c|c|c|c|c|c|c|c|c|}
\hline \multirow{3}{*}{\multicolumn{2}{|c|}{ Question/answer }} & \multicolumn{6}{|c|}{ Settlement } & \multirow{3}{*}{$\mathrm{p}$} \\
\hline & & \multicolumn{2}{|c|}{ Capital } & \multicolumn{2}{|c|}{ District centre } & \multicolumn{2}{|c|}{ Municipal centre } & \\
\hline & & $\mathrm{n}$ & $\%$ & $\mathrm{n}$ & $\%$ & $\mathrm{n}$ & $\%$ & \\
\hline \multirow{5}{*}{$\begin{array}{l}\text { Has the work quality in } \\
\text { the hospital improved, in } \\
\text { relation to the healthcare } \\
\text { social insurance (after } \\
\text { 2000) }\end{array}$} & Yes & 18 & $8,2 \%$ & 12 & $10,3 \%$ & 0 & $0,0 \%$ & \multirow{5}{*}{0,019} \\
\hline & Partly & 74 & $33,6 \%$ & 29 & $25,0 \%$ & 26 & $36,6 \%$ & \\
\hline & No & 106 & $48,2 \%$ & 59 & $50,9 \%$ & 43 & $60,6 \%$ & \\
\hline & No opinion & 20 & $9,1 \%$ & 16 & $13,8 \%$ & 2 & $2,8 \%$ & \\
\hline & Other & 2 & $0,9 \%$ & 0 & $0,0 \%$ & 0 & $0,0 \%$ & \\
\hline
\end{tabular}




\section{CONCLUSIONS}

1. The providers of hospital medical care assess positively the control activity performed by the experts of the National Health Insurance Fund and the methodological assistance they provide during work.

2. Only $1 / 5$ of the respondents share the opinion that control results in improving the provided medical care quality, one in four $(25,8 \%)$ believes control raises the commitment by the officials with managerial positions, one in three $(34,2 \%)$ shares the opinion it raises the commitment by the executives.

3. We established a lack of opinion in many respondents regarding the partnership and the necessary control to be exercised by the National Health Insurance Fund, which focuses our attention on the personnel's awareness concerning the changes in the control system and the more important issue about managing the necessary changes.

4. According to the respondents the new operational terms and conditions inside the health care insurance system do not result in improving the work quality in the hospital, which allows the conclusion that only by changing the healthcare funding the desired positive changes could be initiated. Therefore, we should change the organization, management and provision of medical care.

Recommendations in view of optimizing the control exercised at the hospital medical care level:

1. The policy for quality assurance and control in the healthcare field should aim at improving the common laws and regulations until reaching synchronization with the laws and regulations of the European Union.
2. The establishment of a hierarchically built system for quality assurance, management and control (at national, regional and institutional level) is imperative.

3. Changing control towards the right balance when assessing the medical and economic effectiveness of the services provided in the hospital; and introducing elements of an individual approach case by case. Elaboration of quality criteria for assessment and control of the medical operations is needed.

\section{REFERENCES}

1. Angelov, A. Introduction in management, Trakiya-M, S., 1998, 210-222.

2. Ilieva, A. Control in healthcare, Ciela, S., 2018, p 447.

3. Lazarova, M., Zlatanova T., Zlatanova - Velikova R. Control in healthcare from regulatory point of view, 38th scientifictechnological session Contact 2016, INGA, publishing house TEMTO, pages 101-105.

4. Petrova, ZI. Quality assurance and medical audit - necessary policy at national level", part 1, magazine Health policy and management, 2012, 12, (2), 10-15.

5. Petrova, Zl., Genev Str. Management of the healthcare system, National Association of Healthcare Policy and Management, Health media group, S., 2013, 8-9, 282-284, 290-292.

6. Vodenicharov, Ts. The seven differences between the doctor and the manager, Foundation "Open Society", S., 2003.

7. Vodenicharov, Ts., Borisov V., Gladilov St. et al. Model for effective development of Bulgarian healthcare. Health management, 2008, 8, (1), 53-61.

8. Zlatanova T., Petrova-Gotova Tsv., Popov N et al. Introduction in economic knowledge, GorexPress, Sofia, 2016, page 179.

9. Zlatanova T., Petrova-Gotova Tsv., Popov N et al. Economics of healthcare, GorexPress, Sofia, 2017, p 264.

Received: May, 2019 - Accepted: June, 2019 